\title{
Safety and Mutagenicity Evaluation of Nanoparticulate Red Mold Rice
}

\author{
Chiun-Chieh Yu, ${ }^{\dagger}$ Jyh-Jye Wang,${ }^{\S}$ Chun-Lin Lee, ${ }^{\dagger}$ Shu-Hui LeE, ${ }^{\#}$ And \\ TzU-MING PAN* ${ }^{\dagger}$ \\ Institute of Microbiology and Biochemistry, National Taiwan University, Taipei, Taiwan, \\ Republic of China; Department of Biotechnology, Tajen University, Pingdon, Taiwan, \\ Republic of China; and Animal Health Research Institute, Council of Agriculture, Executive Yuan, \\ TanSwai, Taiwan, Republic of China
}

\begin{abstract}
Nowadays, people have recognized the importance of Monascus fermented products due to their many health benefits. A previous study demonstrated a novel formulation approach for the preparation of nanoparticulate red mold rice (NRMR). The aim of this study is to determine the useability of stable NRMR dispersion by evaluating its safety and mutagenicity with the Ames test. The crude red mold rice $(R M R)$ was processed using a wet milling technology in the presence of distilled water to form an aqueous-based nanoparticle dispersion with a mean particle size of $259.3 \mathrm{~nm}$. The formulated diepersion was found to be homogeneous and exhibited unimodal particle size distribution when analyzed by dynamic laser scattering techniques. Ames test results indicated that the equivalent of up to $1 \mathrm{mg}$ of ethanol extract of RMR per plate exhibited no genotoxicity toward Salmonella typhimurium strains TA 98, TA 100, and TA 102. In the feeding toxicity test, the no observed adverse effect level (NOAEL) of NRMR was found to be $1000 \mathrm{mg} / \mathrm{kg} /$ day for both male and female rats. In conclusion, red mold rice can be formulated as a stable nanoparticulate dispersion using wet milling technology. In vitro and in vivo safety evaluations of NRMR indicated that no mutagenic or toxic responses were observed in this study.
\end{abstract}

KEYWORDS: Monascus; nanoparticulate; safety; mutagenicity

\section{INTRODUCTION}

Monascus, a traditional Chinese fermentation fungus, has been used in many kinds of foods for a thousand years $(1,2)$. Red mold rice (RMR), the common fermented product of Monascus, has been used as a dietary supplement $(2-4)$. The secondary metabolites of red mold rice, including monacolin, $\gamma$-aminobutyric acid (GABA), and dimerumic acid, are known for their health benefits. One of the well-documented metabolites of Monascus is monacolin K (5), which has been identified as an effective cholesterol-lowering agent due to its competitive inhibitory effect against HMG-CoA reductase. In addition, the anti-hypertension effect of $\operatorname{GABA}(3,6)$ and the antioxidant effect of dimerumic acid (7) were also documented in the literature. Although Monascus is capable of producing bioactive compounds, there is the possibility that the hepatonephrotoxic mycotoxin, citrinin, is also produced during red mold rice fermentation as an undesired byproduct $(8,9)$.

Normally speaking, to qualify as a health food, the RMR must be able to improve the absorption of monacolin $\mathrm{K}$ while

* Author to whom correspondence should be addressed (telephone +886-2-33664519; fax +886-2-23627044; e-mail tmpan@ntu.edu.tw).

${ }^{\dagger}$ National Taiwan University.

$\S$ Tajen University.

\# Animal Health Research Institute. reducing its toxicity effect. Many approaches toward these goals have been introduced, for instance, the treatment of RMR with heat, hydrogen peroxide, and strain mutation (10-13). However, heating citrinin under conditions similar to cooking (at 100 and $110{ }^{\circ} \mathrm{C}$ ) was reported to cause the formation of additional cytotoxic compounds (14). In a previous study, we demonstrated a method to prepare nanoparticulate RMR dispersion (15). It is generally accepted that reducing the size of biomaterials to nanometer scale will result in significantly increased surface reactivity, which might broaden their field of applications in medicine and the biotech industry (16). Different forms of nanoparticle formulations have been developed for drug delivering, nanocoating, carrier, and numerous other applications $(17,18)$. However, regardless of their widespread use in industrial and pharmaceutical fields, the public concern for the possible health hazard of nanoparticles against human bodies and environments has been the focus of extensive research (19). It has been shown that nanomaterials can enter and react with the human body when in contact with the lungs, skins, or intestinal tract (20). So far, only a few studies have discussed the toxicity effects of nanomaterials used in foods against animal models (21).

The aim of this study is to determine the feasibility of using wet milling technology to formulate crude RMR into a stable nanoparticulate dispersion by evaluating its safety effect. Red 
mold rice nanoparticulate formulation (NRMR) was prepared by milling RMR in the presence of distilled water. The physical and chemical properties of NRMR particles were studied by electron microscopy, dynamic light scattering, food composition analysis, and high-performance liquid chromatography (HPLC). To perform safety evaluations, an in vitro bacterial mutation test and in vivo 28- and 90-day feeding toxicity tests in Wistar rats were carried out following repeated dosing of NRMR dispersion in this work.

\section{MATERIALS AND METHODS}

Chemicals. RMR used in this study was obtained by solid-state fermentation using Monascus purpureus NTU 568 strain with the characteristics of yielding RMR with relatively high monacolin $\mathrm{K}$ and low citrinin contents (22). The species of the rice used in this study was indica rice (Oryza sativa L. spp. indica). For the wet milling process, the yttria-stabilized zirconia grinding medium purchased from Toray Industries, Inc. (Chuo-ku, Tokyo, Japan) was used. For HPLC, all solvents used were of HPLC grade. Monacolin K and citrinin standards were purchased from Sigma-Aldrich Fine Chemicals (St. Louis, MO). For bacterial gene mutation, D-glucose-6-phosphate, $\beta$-nicotinamide adenine dinucleotide phosphate (NADP), L-histidine, D-biotin, 4-nitroquinoline- $N$-oxide (4NQO), benzo[a]pyrene (B[a]P), 2-aminoanthracene, and methyl methanesulfonate were purchased from Sigma-Aldrich Fine Chemicals, whereas dimethyl sulfoxide (DMSO) and D-glucose were purchased from Wako Pure Chemicals (Osaka, Japan). S-9 was purchased from ICN Biomedicals, Inc. (Irvine, CA). Oxoid no. 2 nutrient broth was purchased form Oxoid Ltd. (Basingstoke Hampshire, U.K.).

Formulation of NRMR Dispersion. NRMR dispersions were prepared according to our previously published method (15), but with minor modification, and is described as follows. At first, the dried RMR was ground into flour, weighed $(20 \mathrm{~g})$, and stirred gently for $30 \mathrm{~min}$ with $200 \mathrm{~mL}$ of distilled water. The crude RMR slurry was added to a roller mill jar containing zirconia beads $(600 \mathrm{~g})$ and was placed on the NM0010 ballmill (Fu Chun Shin Co., Tainan, Taiwan). The wet milling process was carried out by in three steps. The crude RMR was first milled with $0.65 \mathrm{~mm}$ zirconia beads for $1 \mathrm{~h}$, followed by milling with $0.2 \mathrm{~mm}$ zirconia beads for $0.5 \mathrm{~h}$, and finally with $0.1 \mathrm{~mm}$ zirconia beads for $1 \mathrm{~h}$. Ball-milling was performed at $3000 \mathrm{rpm}$, and the power output of the mill was $80 \mathrm{~W}$. The NRMR dispersion was collected and subjected to particle size determination (23) and secondary metabolites content (24) and food composition analysis, which included the water, ash, lipid, protein, and carbohydrate contents.

Preparation of Ethanol Extracts from RMR and NRMR Products. With a minor modification of the previously published methods $(25,26)$, nanoparticulate RMR and nonmilling RMR product were first freeze-dried in the vacuum; then $2 \mathrm{~g}$ of the freeze-dried powder was transferred to a flask, and $20 \mathrm{~mL}$ of extraction solvent (ethanol) was added to the flask immediately. The mixture was shaken for 90 min in a $65{ }^{\circ} \mathrm{C}$ water bath and then centrifuged at $5300 \mathrm{~g}$ for $20 \mathrm{~min}$ at room temperature. The supernatant solution was collected and allowed to dry in a hood. The dried solid was dissolved in $2 \mathrm{~mL}$ of DMSO; each $1 \mu \mathrm{L}$ of the yielded DMSO solution contains roughly the equivalent of ethanol extract from $1 \mathrm{mg}$ of the freeze-dried NRMR, or nonmilling RMR powder.

Bacterial Gene Mutagenicity Test (Ames Test). The Ames test was performed by using Salmonella typhimurium strains TA 98 (frameshift), TA 100 (base pair substitution), and TA 102 (transitions/ transversion). The mutagenicity of the selected bacterial strains, with or without metabolic activation, was tested by treating with RMR suspensions together with positive reference compounds. Overnight cultures containing $1 \times 10^{8}$ microorganisms prepared from stock cultures were used for all assays. Filtered extracts of RMR samples were dissolved in DMSO to form solution with final concentrations equal to $0,0.5,1.5$, and $10 \mathrm{mg} / \mathrm{mL}$. Samples of each concentration were tested in triplicate. The methodology of the Ames assay was described in detail by Maron, Ames, and the Organization for Economic Cooperation and Development (OECD) $(27,28)$. In brief, $0.1 \mathrm{~mL}$ of the DMSO-soluble sample was first added to culture tubes containing $2.0 \mathrm{~mL}$ of top agar and $0.1 \mathrm{~mL}$ of tester strain suspension. Then, the sample-loaded cultures were plated. For the microsomal activated assay, $0.5 \mathrm{~mL}$ of $\mathrm{S} 9 \mathrm{mix}$ was added to the culture tubes after the addition of the bacteria. All plates were read after $48 \mathrm{~h}$.

Repeated-Dose 28-Day and 90-Day Oral Toxicity Study in Rats (29, 30). Animal Grouping and Experiment Design. Male and female Wistar rats aged 8 weeks were obtained from the Laboratory Animal Center of College of Medicine, National Taiwan University. They were kept in a temperature-controlled room $\left(21 \pm 2{ }^{\circ} \mathrm{C}\right)$ under a $12 \mathrm{~h}$ light/12 h dark cycle (light on at 6:00 a.m.) and were given free access to food and water. The diet was in the form of the American Institute of Nutrition (AIN) diet (31), and water (supplied in bottles) was available ad libitum throughout the acclimatization and treatment periods. Food consumption was recorded weekly. Two rats (of the same sex) were housed in a cage throughout the study. In the experiment, 100 rats were divided into five groups (10 males and 10 females per group) including a control group (double-distilled water) and were given $100 \mathrm{mg} / \mathrm{kg}$ of body wt/day nonmilling RMR $(1 \times), 100 \mathrm{mg} / \mathrm{kg}$ of body wt/day NRMR $(1 \times), 500 \mathrm{mg} / \mathrm{kg}$ of body wt/day NRMR $(5 \times)$, and 1000 $\mathrm{mg} / \mathrm{kg}$ of body wt/day NRMR $(10 \times)$, respectively. Clinical observations, body weights, and food consumption were recorded. At the end of the scheduled period, the tested animals were sacrificed and subjected to a full post-mortem examination. Cardiac blood samples were taken for clinical pathology, selected organs were weighed, and then specified tissues were taken for subsequent histological examination.

Preparation of Feeding Samples. The NRMR dispersion was prepared by the wet milling process, and the resulting dispersion was then diluted with distilled water to achieve the desired concentrations. The concentration of the feeding samples was determined prior to the feeding. The dispersions were stirred during dosing, and the dosing volume was $5 \mathrm{~mL} / \mathrm{kg}$ of body weight.

Clinical Pathology. At the end of the 28- and 90-day feeding periods, blood samples for hematology and clinical chemistry tests were taken at necropsy for all rats using cardiac puncture under carbon dioxide inhalation $[1 \mathrm{~mL}$ into ethylenediaminetetraacetic acid (EDTA) for hematology, $2 \mathrm{~mL}$ into sodium citrate (3.2\%) for clotting times, and 2 $\mathrm{mL}$ for blood clinical chemistry]. The following hematological parameters were measured on the EDTA-anticoagulated samples using a semiautomated hematology analyzer (Sysmex F-800, Kobe, Japan): hemoglobin, red blood cell count, mean cell hemoglobin, mean cell hemoglobin concentration, mean cell volume, hematocrit, platelet count, and total white blood cell count. Blood cell morphology and differential white blood cell count were assessed by automated methods. Clotting measurements, for prothrombin time and activated partial thromboplastin time (APTT), were performed on the blood samples collected in tubes containing sodium citrate as an anticoagulant.

The following clinical chemistry measurements were performed on the plasma from the blood samples collected into tubes: alkaline phosphatase, alanine aminotransferase, aspartate aminotransferase, $\gamma$-glutamyl transferase, albumin, bilirubin, creatinine, urea nitrogen, glucose, phosphorus, calcium, chloride, potassium, sodium, total protein, triglyceride, and cholesterol. All parameters were measured using a clinical chemistry analyzer (Beckman-700, Fullerton, CA). The range of the clinical chemistry parameters measured were wide enough to cover the possible effects of toxicities, electrolyte balance, and metabolism (carbohydrate, protein, and fat) and to cover the possible damage to the major organ systems. The experiment was reviewed and approved by the Animal Care and Research Ethics Committee of the National Taiwan University.

Pathology Examinations. In the 28-day feeding study, all rats were anesthetized and sacrificed through carbon dioxide inhalation and were subjected to full post-mortem examination. At necropsy, the following organs were weighed (paired organs were weighed together): adrenals, liver, kidneys, and gonads. The following tissues were examined in situ, removed, and fixed into $10 \%$ buffered formalin: adrenal glands, heart, liver, kidneys, and spleen.

In the 90-day feeding study, the following organs were weighed: liver, adrenals, kidneys, gonads, heart, and brain at necropsy. The following tissues were examined in situ, removed, and fixed into $10 \%$ buffered formalin: adrenals, aorta, bone marrow, brain, small intestine, 

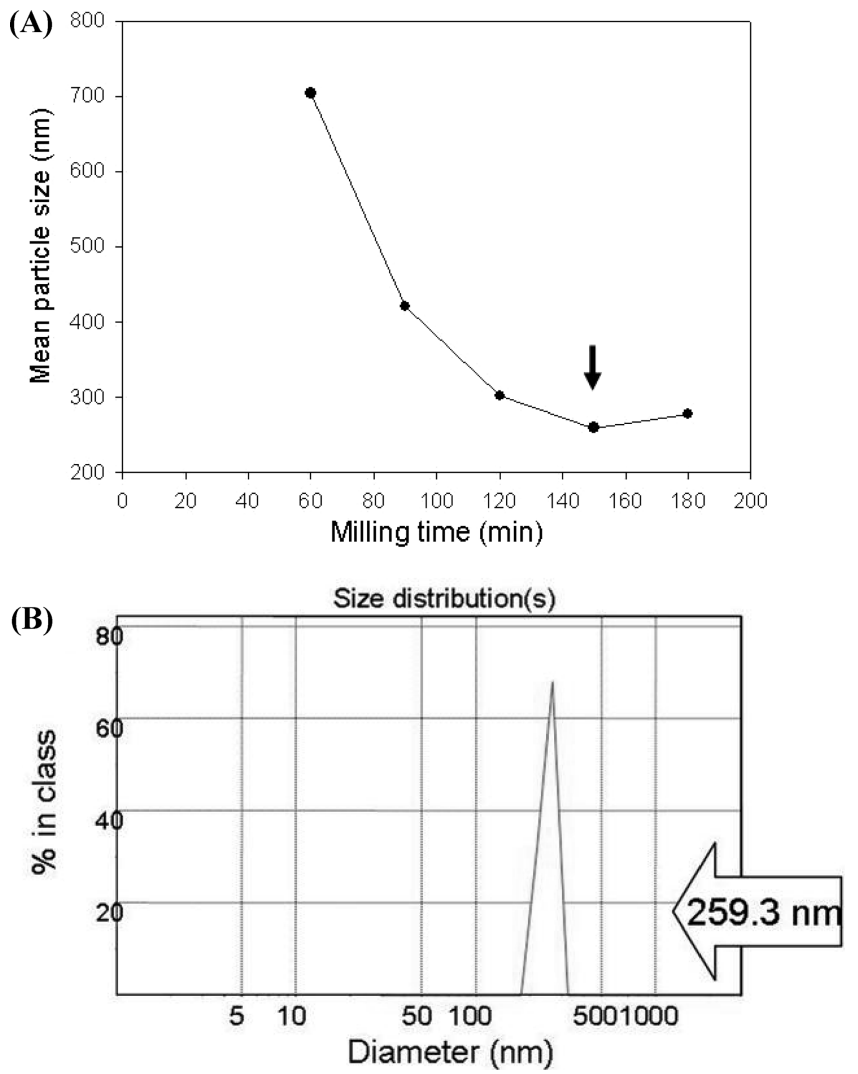

Figure 1. Particle size reduction/time curve of red mold rice fermented with Monascus purpureus NTU 568 dispersion processed using a threestep wet milling process: $(\mathbf{A})$ three-step milling process (processed by $0.65 \mathrm{~mm}$ grinding media for $1 \mathrm{~h}, 0.2 \mathrm{~mm}$ grinding media for $0.5 \mathrm{~h}$, and then $0.1 \mathrm{~mm}$ grinding media for $1 \mathrm{~h}$ ); (B) particle size distribution of $M$. purpureus NTU 568 red mold rice after the three-step milling process.

large intestine, esophagus, heart, kidneys, liver, trachea, lung(s), lymph nodes, ovaries/testes, pancreas, peripheral nerve, pituitary, prostate, spinal cord, spleen, stomach, thymus, thyroids/parathyroids, urinary bladder, and uterus. All tissues from the high-dose and control groups were routinely processed, embedded in paraffin wax, stained with hematoxylin and eosin, and examined by light microscopy.

Statistical Analyses. The SPSS Statistical System was used to analyze chemical pathology, organ weight, food consumption, and body weight data, followed by testing for variance (ANOVA). In this work, the statements of statistical significance were based on $p<0.05$ when indicating the significance of differences between the control and treated groups. These analyses were accomplished by using statistical analysis software configured for a computer (SPSS, release 9.0, SPSS, Inc., Cary, $\mathrm{NC})$.

\section{RESULTS}

Formulation of NRMR Dispersion. M. purpureus NTU 568 strain was used to produce RMR product through solid-state fermentation. The wet milling process for RMR was modified into three steps (milled with $0.65 \mathrm{~mm}$ grinding beads for $1 \mathrm{~h}$, $0.2 \mathrm{~mm}$ grinding beads for $0.5 \mathrm{~h}$, and $0.1 \mathrm{~mm}$ grinding beads for another $1 \mathrm{~h}$ ). As can be seen in Figure 1, the consecutive milling of the RMR dispersion with three different sizes of grinding media resulted in a very homogeneous NRMR dispersion with a mean particle size equal to $259.3 \mathrm{~nm}$. The results were obtained from dynamic laser scattering measurement, and the average size of nanoparticles was calculated by the scattered intensity fluctuations on the time scale. In food composition analysis, RMR was determined to contain $57.83 \%$ carbohydrate, $31.27 \%$ protein, $3.05 \%$ fat, $5.38 \%$ moisture, and $2.47 \%$ ash. In addition, the concentrations of the secondary metabolites

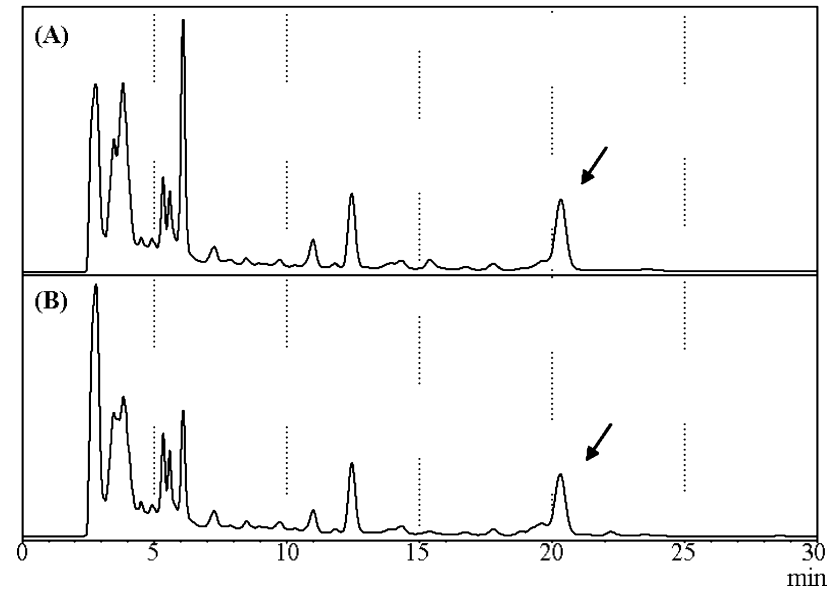

Figure 2. HPLC profiles of monacolin $\mathrm{K}$ before and after the three-step milling process showing retention times of $20.33 \mathrm{~min}$ : (A) monacolin $\mathrm{K}$ content extracted from unmilled RMR is $7514 \mathrm{mg} / \mathrm{kg}$; (B) monacolin K content extracted from NRMR is $5651 \mathrm{mg} / \mathrm{kg}$.

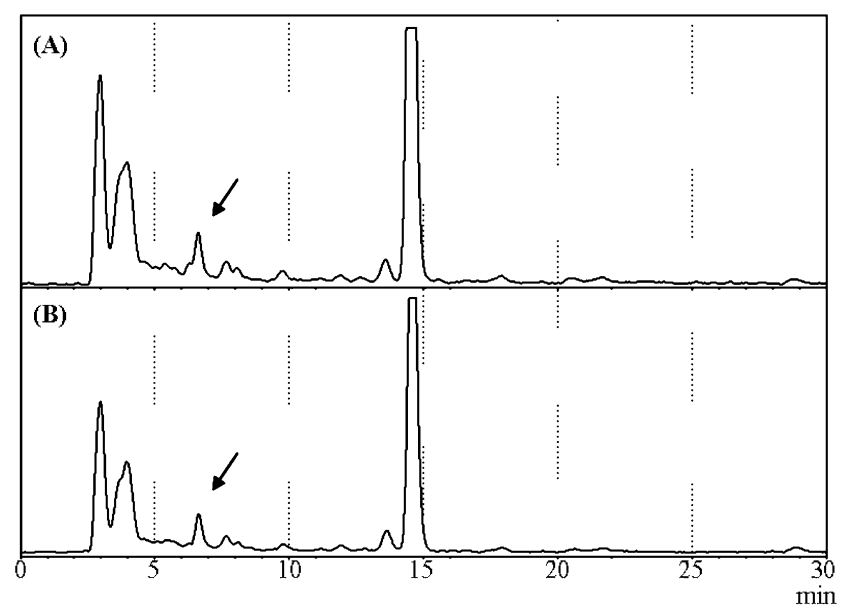

Figure 3. HPLC profiles of citrinin before and after the three-step milling process showing retention times of $6.61 \mathrm{~min}$ : (A) citrinin content extracted from unmilled RMR is $1405 \mu \mathrm{g} / \mathrm{kg}$; (B) monacolin $\mathrm{K}$ content extracted from NRMR is $1048 \mu \mathrm{g} / \mathrm{kg}$.

originated from either the unprocessed or processed RMR particles were studied using HPLC as shown in Figures 2 and 3.

The HPLC profiles of monacolin $\mathrm{K}$ revealed that the major peak occurred at the retention time of $20.33 \mathrm{~min}$ as shown in Figure 2. The amout of monacolin $\mathrm{K}$ extracted was found to reduce from $7514 \mathrm{mg} / \mathrm{kg}$ in the unprocessed RMR to $5651 \mathrm{mg} /$ $\mathrm{kg}$ in the processed RMR. In Figure 3, the HPLC profiles of citrinin showed that its major peak occurred at the retention time of $6.61 \mathrm{~min}$. The amount of citrinin extracted was found to reduce from 1405 to $1048 \mu \mathrm{g} / \mathrm{kg}$.

Bacterial Gene Mutagenicity Test (Ames Test). To ensure the credibility and accuracy of the test strains, the gene patterns of S. typhimurium strains TA 98, TA 100, and TA 102 were confirmed to maintain their specific genotypes for the subsequent experiments. Table 1 shows the results of the Salmonella microsome assay treated with ethanol extract of nonmilling RMR and NRMR. No mutagenicity was detected, either with or without metabolic activation by $\mathrm{S} 9 \mathrm{mix}$, for dose levels ranging from 50 to $1000 \mu \mathrm{g} / \mathrm{plate}$. Positive controls were included in the experiments and resulted in correct results.

Repeated-Dose 28-Day Oral Toxicity Study in Rats. According to our observation, treatment with NRMR did not affect the mortality or clinical signs of tested rats. No statistically 
Table 1. Mutagenicity of Alcohol Extract of Nanoparticulate Red Mold Rice against Salmonella typhimurium Strains TA 98, TA 100, and TA 102

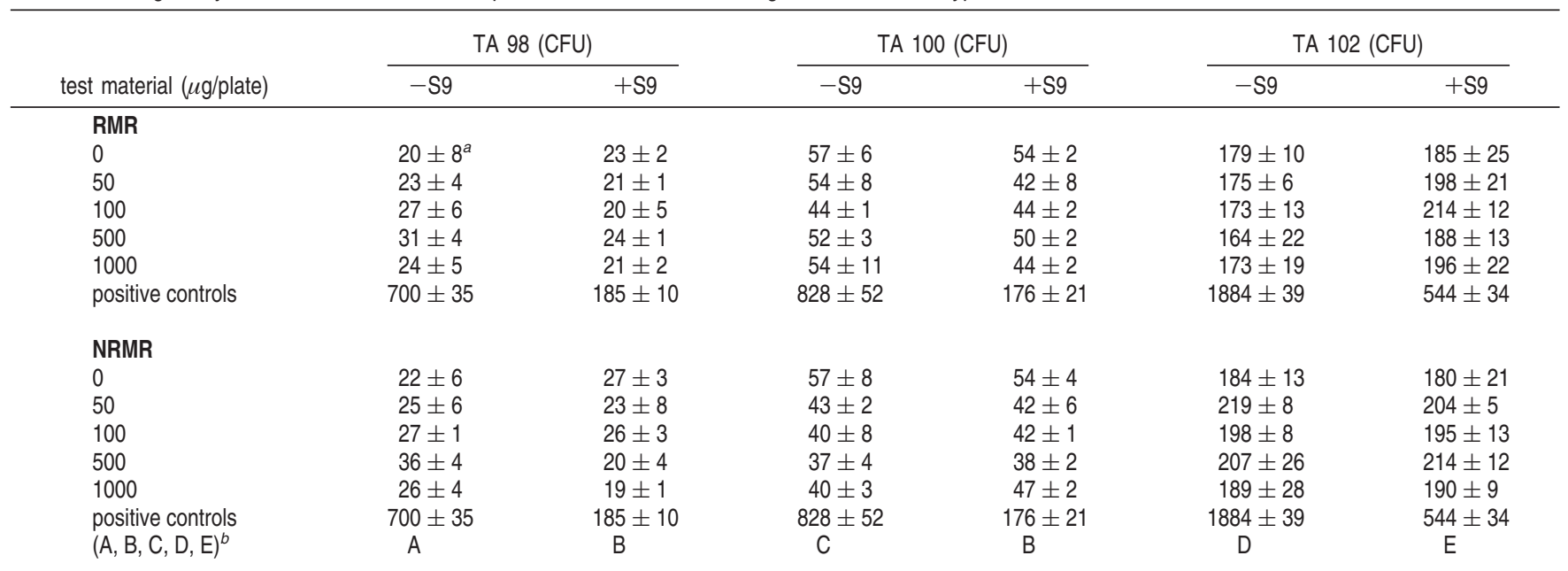

${ }^{a}$ Values are means $\pm \mathrm{SD}$ of his $^{+}$revertants per plate. ${ }^{b}$ Mutagens used in positive control plate: A, 4-nitroquinoline $\mathrm{N}$-oxide (1 $\mu \mathrm{g} /$ plate); B, benzo[a]pyrene $(2.5$ $\mu \mathrm{g} /$ plate); C, 4-nitroquinoline $\mathrm{N}$-oxide (0.1 $\mu \mathrm{g} /$ plate); D, methyl methanesulfonate $(1 \mu \mathrm{g} / \mathrm{plate})$; E, 2-aminoanthracene (10 $\mu \mathrm{g} / \mathrm{plate})$.

Table 2. Changes of Hematological Parameters in Male and Female Rats Treated with Red Mold Rice and Nanoparticulate Red Mold Rice by Gastric Gavage Consecutively for 28 Days $^{a}$

\begin{tabular}{|c|c|c|c|c|c|}
\hline & control & RMR (100 mg/kg) & \multicolumn{3}{|c|}{ NRMR dose concn } \\
\hline \multicolumn{6}{|c|}{ Male } \\
\hline $\mathrm{Hb}(\mathrm{g} / \mathrm{dL})$ & $16.91 \pm 2.10$ & $17.15 \pm 1.10$ & $16.56 \pm 0.75$ & $16.04 \pm 0.44$ & $16.02 \pm 0.44$ \\
\hline WBC $\left(10^{9} / \mathrm{L}\right)$ & $17.64 \pm 1.62$ & $15.56 \pm 1.24^{*}$ & $16.83 \pm 2.66$ & $17.88 \pm 1.64^{*}$ & $16.44 \pm 1.64^{*}$ \\
\hline Hct $(\%)$ & $56.40 \pm 8.36$ & $57.40 \pm 3.80$ & $54.20 \pm 1.64$ & $52.59 \pm 1.26$ & $51.66 \pm 1.26$ \\
\hline MCV (fL) & $61.94 \pm 1.64$ & $62.48 \pm 1.54$ & $62.55 \pm 1.49$ & $61.44 \pm 1.49$ & $61.99 \pm 1.49$ \\
\hline platelets $\left(10^{9} / \mathrm{L}\right)$ & $954.95 \pm 161.51$ & $948.10 \pm 82.81$ & $906.05 \pm 98.44$ & $951.70 \pm 134.65$ & $953.23 \pm 134.65$ \\
\hline NB $\left(10^{9} / \mathrm{L}\right)$ & $0.95 \pm 0.80$ & $1.25 \pm 0.77$ & $0.90 \pm 0.77$ & $0.80 \pm 0.68$ & $0.95 \pm 0.68$ \\
\hline NS $\left(10^{9} / \mathrm{L}\right)$ & $21.00 \pm 2.88$ & $20.45 \pm 2.82$ & $19.25 \pm 2.59$ & $22.85 \pm 3.13$ & $24.32 \pm 3.13^{*}$ \\
\hline lymphocytes $\left(10^{9} / \mathrm{L}\right)$ & $76.15 \pm 3.66$ & $76.50 \pm 3.79$ & $78.00 \pm 3.32$ & $74.50 \pm 3.88$ & $72.68 \pm 3.88^{*}$ \\
\hline monocytes $\left(10^{9} / \mathrm{L}\right)$ & $1.35 \pm 0.65$ & $1.25 \pm 0.54$ & $1.20 \pm 0.60$ & $1.20 \pm 0.60$ & $1.23 \pm 0.60$ \\
\hline eosinophils $\left(10^{9} / \mathrm{L}\right)$ & $0.55 \pm 0.67$ & $0.55 \pm 0.59$ & $0.65 \pm 0.73$ & $0.60 \pm 0.58$ & $0.82 \pm 0.58$ \\
\hline $\operatorname{Hct}(\%)$ & $53.90 \pm 3.46$ & $57.11 \pm 4.44^{*}$ & $53.96 \pm 3.02$ & $53.08 \pm 3.30$ & $51.23 \pm 3.22$ \\
\hline MCV (fL) & $63.19 \pm 2.11$ & $63.08 \pm 1.71$ & $62.08 \pm 2.03$ & $63.04 \pm 2.14$ & $61.06 \pm 1.77^{\star}$ \\
\hline $\mathrm{MCH}(\mathrm{pg})$ & $19.50 \pm 0.68$ & $19.00 \pm 0.44$ & $19.35 \pm 0.64$ & $19.69 \pm 0.93$ & $19.15 \pm 0.70$ \\
\hline $\mathrm{MCHC}(\mathrm{g} / \mathrm{dL})$ & $30.85 \pm 0.57$ & $30.14 \pm 0.38^{*}$ & $31.18 \pm 0.65$ & $31.22 \pm 0.67$ & $31.37 \pm 0.68^{*}$ \\
\hline platelets $\left(10^{9} / \mathrm{L}\right)$ & $943.90 \pm 117.17$ & $980.39 \pm 117.78$ & $988.70 \pm 115.51$ & $962.00 \pm 236.36$ & $917.64 \pm 118.34$ \\
\hline NB $\left(10^{9} / \mathrm{L}\right)$ & $0.70 \pm 0.78$ & $1.44 \pm 0.50^{\star}$ & $1.40 \pm 0.58^{\star}$ & $1.20 \pm 0.68$ & $1.27 \pm 0.75^{\star}$ \\
\hline NS $\left(10^{9} / \mathrm{L}\right)$ & $19.30 \pm 4.21$ & $21.83 \pm 2.22$ & $22.25 \pm 3.40$ & $22.50 \pm 3.92^{*}$ & $21.36 \pm 4.41$ \\
\hline lymphocytes $\left(10^{9} / \mathrm{L}\right)$ & $78.50 \pm 5.32$ & $74.56 \pm 2.22$ & $74.45 \pm 4.20^{*}$ & $74.55 \pm 5.33^{*}$ & $75.64 \pm 5.71$ \\
\hline monocytes $\left(10^{9} / \mathrm{L}\right)$ & $1.15 \pm 0.65$ & $1.22 \pm 0.42$ & $1.25 \pm 0.54$ & $1.00 \pm 0.95$ & $1.09 \pm 0.67$ \\
\hline eosinophils $\left(10^{9} / \mathrm{L}\right)$ & $0.35 \pm 0.57$ & $0.94 \pm 0.78^{*}$ & $0.65 \pm 0.65$ & $0.75 \pm 0.77$ & $0.59 \pm 0.65$ \\
\hline basophils $\left(10^{9} / \mathrm{L}\right)$ & $0.00 \pm 0.00$ & $0.00 \pm 0.00$ & $0.00 \pm 0.00$ & $0.00 \pm 0.00$ & $0.00 \pm 0.00$ \\
\hline
\end{tabular}

\footnotetext{
${ }^{a}$ Data are presented as mean \pm SD $(n=10)$. Mean values within each column with an asterisk are significantly different $(p<0.05)$. RBC, red blood cells; Hb, hemoglobin; WBC, white blood cells; Hct, hematocrit; MCV, mean cell volume; MCH, mean cell hemoglobin; MCHC, mean cell hemoglobin concentration; NB, neutrophil
} band; NS, neutrophil segment.

significant difference in mean body weights was observed between any tested groups. No significant difference in food consumption was found between the treated and the control groups (data not shown), and the data in Table 2 indicate the presence of statistically significant differences in hematology between male and female rats. However, none of the above differences were considered to be toxicologically significant. Compared with the reference values of the male rats in the control group, the values of white blood cell (WBC) and lymphocytes count were significantly lower, whereas the values of mean cell hemoglobin, mean cell hemoglobin concentration, and neutrophils (segment form) were significantly higher in the high-dose NRMR-treated group. However, when compared with the hematology and clinical chemistry reference value of normal Wistar rats, listed in the technical bulletin of Charles River Laboratories (32) and Guide to the Care and Use of Experimental Animals (33), the deviation of the treated group data from those of the control group was considered to be very minor and within the physiologically acceptable range of reference values for normal Wistar male rats. In female rats, the mean 
Table 3. Serum Biochemistry Change of Male and Female Rats Treated with Red Mold Rice and Nanoparticulate Red Mold Rice by Gastric Gavage Consecutively for 28 Days $^{a}$

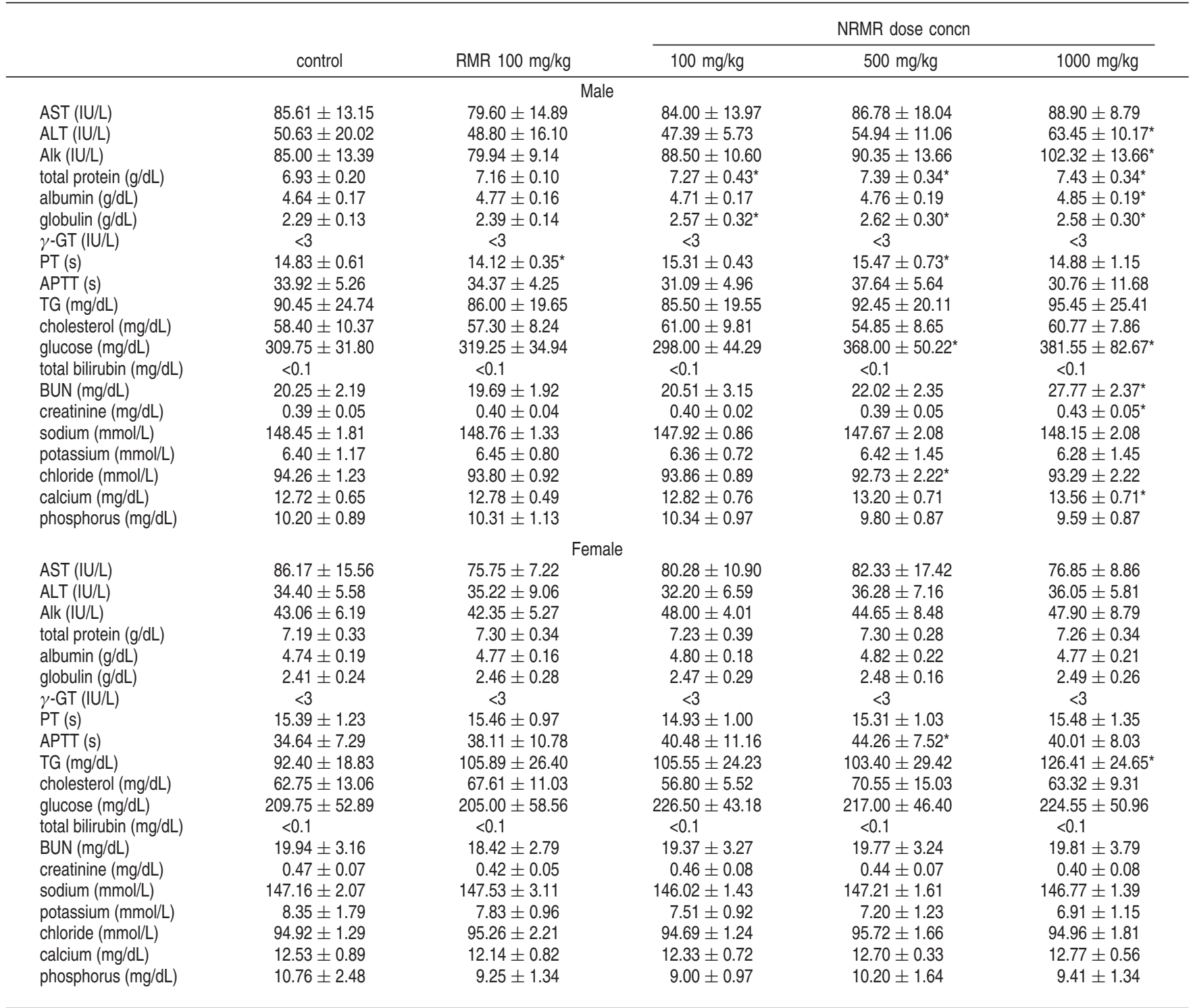

${ }^{a}$ Data are presented as mean $\pm \mathrm{SD}(n=10)$. Mean values within each column with an asterisk are significantly different $(p<0.05)$. AST, aspartate aminotransferase; ALT, alanine aminotransferase; Alk, alkaline phosphatase; $\gamma$-GT, $\gamma$-glutamyl transpeptidase; PT, prothrombin time; APTT, activated partial thromboplastin time; TG, triglycerides; BUN, blood urea nitrogen.

cell volume was significantly lower and the mean cell hemoglobin concentration was significantly higher in the high-dose NRMR-treated group than in the control group. Nevertheless, the deviation of the data is still within the physiologically acceptable range of reference values for normal Wistar female rats and was not considered to be biologically significant.

Clinical chemistry analysis showed minor statistically significant differences between the treated male and female rats and the control group (Table 3). In male rats, the values of alanine aminotransferase, alkaline phosphatase, total protein, albumin, globulin, glucose, blood urea nitrogen (BUN), creatine, and calcium were significantly higher in the high-dose NRMRtreated groups than in the control group. By comparison of the data with the reference values of normal rats, it was found that the tested values for alanine aminotransferase, glucose, and BUN fell out of the physiologically acceptable reference value of normal rats. However, in the absence of significant changes in organ weight or histopathological parameters in these animals, these minor changes in clinical chemistry parameters were considered to be of no biological or toxicological significance.
In female rats, the values of triglycerides (TG) and activated partial thromboplastin time in the high-dose NRMR-treated group were found to be significantly different from the values of the control group. However, the deviation of data was still within the physiologically acceptable reference values of normal Wistar female rats and was not considered to be biologically significant. In terms of the effect of NRMR treatment on coagulation, no statistically significant difference in prothrombin time was observed between the treated and control groups. Likewise, after 28days of treatment, no statistically significant change in organ weights was observed between the control and treated groups (Table 4). For animals that survived until termination, there were no macroscopic changes at necropsy that could be attributed to the administration of high-dose NRMR. Similarly, as shown in Figures 4 and 5, no corresponding gross or microscopic pathological changes in these organs were observed.

Repeated-Dose 90-Day Oral Toxicity Study in Rats. On the basis of our clinical observations, the NRMR treatment did not significantly affect the mortality or clinical signs of the tested 
Table 4. Organ Weight Variation of Male and Female Rats Treated with Red Mold Rice and Nanoparticulate Red Mold Rice by Gastric Gavage Consecutively for 28 and 90 Days $^{a}$

\begin{tabular}{|c|c|c|c|c|c|}
\hline & control & RMR $100 \mathrm{mg} / \mathrm{kg}$ & \multicolumn{3}{|c|}{ NRMR dose concn } \\
\hline \multicolumn{6}{|c|}{ Male, 28 Days } \\
\hline kidney(s) & $2.864 \pm 0.220$ & $2.972 \pm 0.386$ & $2.926 \pm 0.337$ & $3.000 \pm 0.149$ & $2.730 \pm 0.250$ \\
\hline testes & $3.652 \pm 0.256$ & $3.727 \pm 0.327$ & $3.822 \pm 0.361$ & $3.810 \pm 0.148$ & $3.654 \pm 0.281$ \\
\hline liver & $11.112 \pm 0.987$ & $11.871 \pm 1.729$ & $11.605 \pm 1.521$ & $11.825 \pm 1.083$ & $10.483 \pm 2.276$ \\
\hline kidney(s) & $1.729 \pm 0.138$ & $1.854 \pm 0.182$ & $1.892 \pm 0.131$ & $1.769 \pm 0.200$ & $1.724 \pm 0.103$ \\
\hline ovaries & $0.099 \pm 0.029$ & $0.093 \pm 0.030$ & $0.111 \pm 0.038$ & $0.101 \pm 0.038$ & $0.079 \pm 0.011$ \\
\hline liver & $6.855 \pm 0.566$ & $7.191 \pm 0.768$ & $7.159 \pm 0.797$ & $7.131 \pm 0.902$ & $6.648 \pm 0.374$ \\
\hline \multicolumn{6}{|c|}{ Male, 90 Days } \\
\hline adrenal & $0.050 \pm 0.013$ & $0.050 \pm 0.011$ & $0.054 \pm 0.015$ & $0.056 \pm 0.013$ & $0.059 \pm 0.013$ \\
\hline kidney(s) & $3.035 \pm 0.205$ & $3.131 \pm 0.159$ & $3.120 \pm 0.258$ & $3.073 \pm 0.311$ & $2.895 \pm 0.202$ \\
\hline testes & $3.540 \pm 0.398$ & $3.565 \pm 0.359$ & $3.587 \pm 0.539$ & $3.545 \pm 0.411$ & $3.652 \pm 0.218$ \\
\hline \multicolumn{6}{|c|}{ Female, 90 Days } \\
\hline adrenal & $0.080 \pm 0.011$ & $0.077 \pm 0.013$ & $0.073 \pm 0.018$ & $0.068 \pm 0.015$ & $0.070 \pm 0.015$ \\
\hline kidney(s) & $1.928 \pm 0.177$ & $1.935 \pm 0.094$ & $1.824 \pm 0.134$ & $1.851 \pm 0.133$ & $1.903 \pm 0.173$ \\
\hline ovaries & $0.096 \pm 0.022$ & $0.091 \pm 0.017$ & $0.100 \pm 0.025$ & $0.094 \pm 0.026$ & $0.091 \pm 0.018$ \\
\hline liver & $7.625 \pm 0.741$ & $7.074 \pm 0.597$ & $6.953 \pm 0.784$ & $7.153 \pm 0.586$ & $7.311 \pm 0.820$ \\
\hline heart & $0.873 \pm 0.087$ & $0.919 \pm 0.113$ & $0.858 \pm 0.105$ & $0.877 \pm 0.104$ & $0.880 \pm 0.117$ \\
\hline brain & $2.015 \pm 0.132$ & $2.009 \pm 0.087$ & $2.082 \pm 0.050$ & $1.908 \pm 0.033$ & $1.955 \pm 0.043$ \\
\hline
\end{tabular}

${ }^{a}$ Data are presented as mean \pm SD $(n=10)$.

(A1)

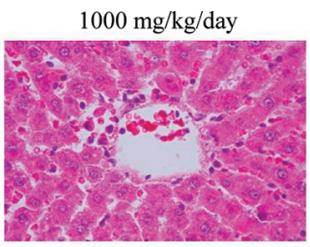

(A2)

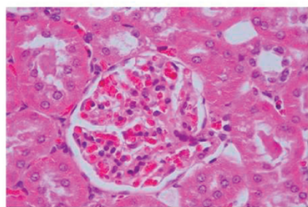

(A3)

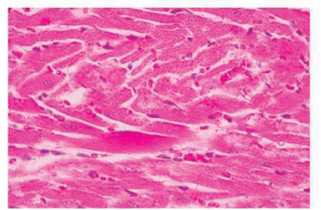

(A4)

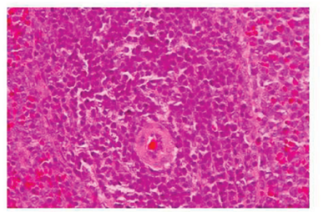

(A5)

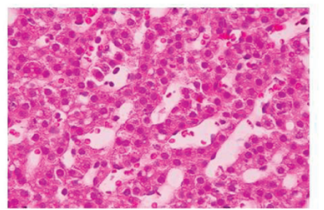

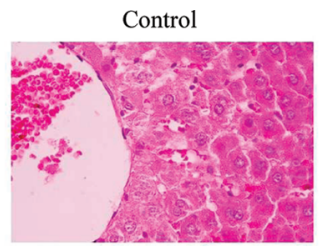
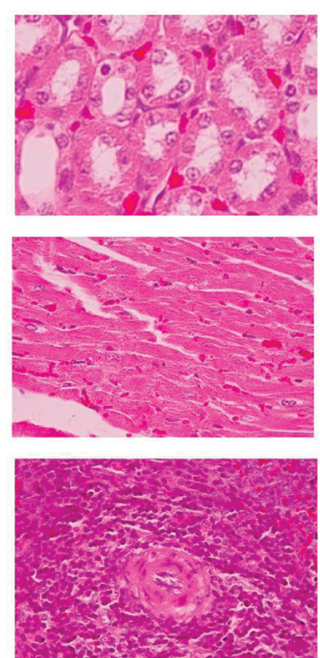

(B3)

Heart

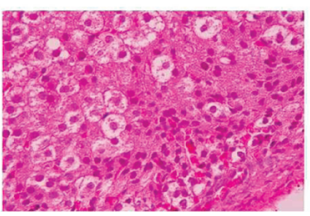

(B5)

Adrenal gland

Figure 4. Histopathological findings of different organs in male rats (at a $400 \times$ magnification): (A) high-dose NRMR-treated group (1000 mg/kg rat); (B) normal diet group.

rats. No statistically significant difference in mean body weights was detected between any tested groups. Food consumption in the treated groups was not significantly different from that of
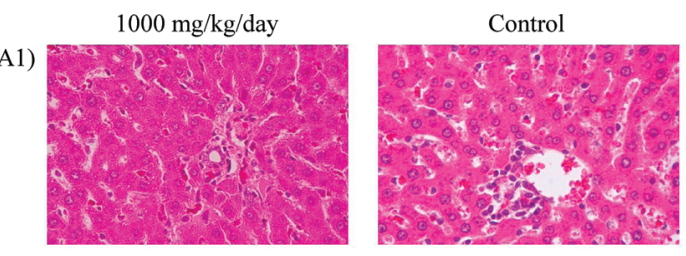

(B1)

(A2)
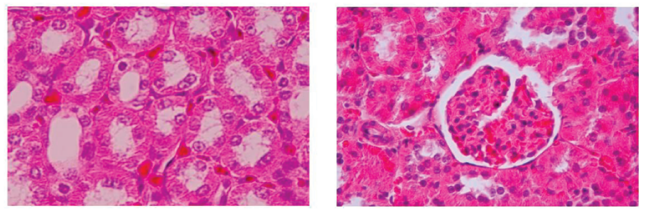

(B2)

(A3)
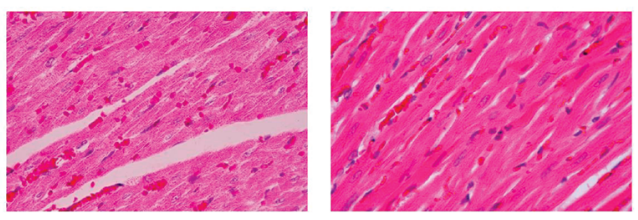

(B3)

(A4)
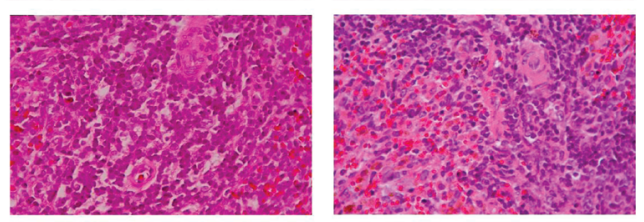

(B4)

(A5)
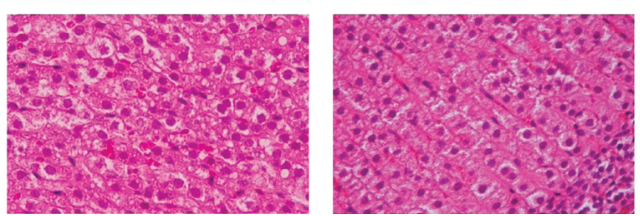

(B5)

Adrenal

gland

Figure 5. Histopathological findings of different organs in female rats (at a $400 \times$ magnification): (A) high-dose NRMR-treated group (1000 mg/kg rat); (B) normal diet group.

the control group (data not shown). Some statistically significant changes in minor hematology parameters for male and females rats are shown in Table $\mathbf{5}$, but none of these change were considered to be of toxicological significance. Slightly reduced 
Table 5. Changes of Hematological Parameters in Male and Female Rats Treated with Red Mold Rice and Nanoparticulate Red Mold Rice Consecutively for 90 Days $^{a}$

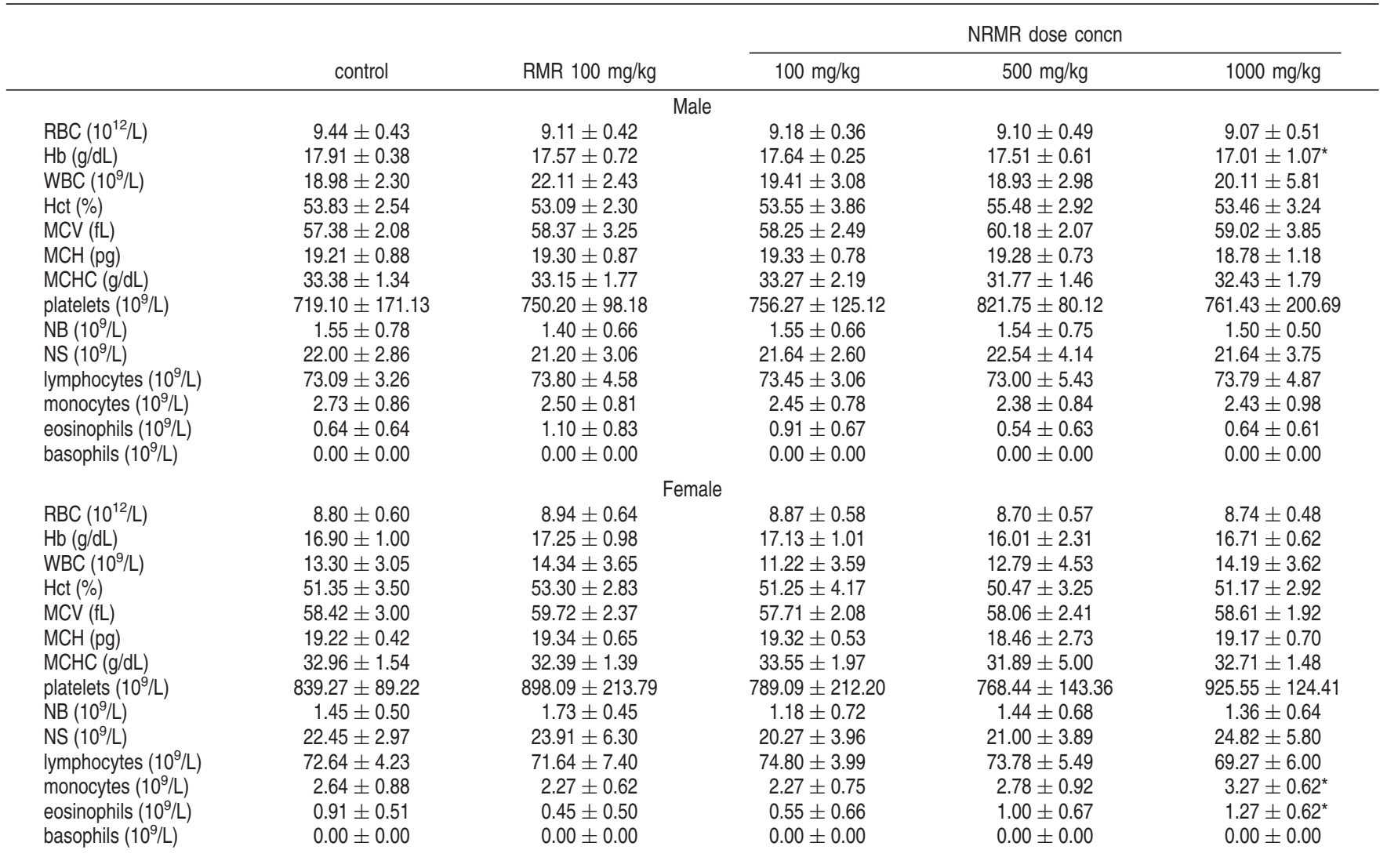

${ }^{a}$ Data are presented as mean $\pm \mathrm{SD}(n=10)$. Mean values within each column with an asterisk are significantly different $(p<0.05)$. RBC, red blood cells; Hb, hemoglobin; WBC, white blood cells; Hct, hematocrit; MCV, mean cell volume; MCH, mean cell hemoglobin; MCHC, mean cell hemoglobin concentration; NB, neutrophil band; NS, neutrophil segment.

hemoglobin was detected for male rats treated with high-dose NRMR when compared to the control rats. In female rats, the values of monocytes and eosinophils in the high-dose NRMRtreated group were significantly higher than in the control group. Nevertheless, according to the hematology and clinical chemistry reference value of normal Wistar rats listed in the technical bulletin of Charles River Laboratories (32) and Guide to the Care and Use of Experimental Animals (33), the data were still within the physiologically acceptable range of reference values for normal Wistar rats and were not considered to be biologically significant.

Clinical chemistry analysis revealed the presence of minor statistically significant differences in some parameters between the treated male groups and the control group as shown in Table 6, yet these data were considered to be of no biological or toxicological significance for male rats. Similarly, in female rats, the values of sodium, potassium, and calcium were significantly different between the high-dose NRMR-treated groups and the control group. Again, the data were still within the physiologically acceptable range of reference values for normal Wistar female rats and were not considered to be biologically significant. In terms of the NRMR-induced coagulation effect, no statistically significant differences for prothrombin time or activated partial thromboplastin time in all groups were observed between the treated and control groups.

After 90 days of treatment, no statistically significant change in organ weights was observed between the treated and the control groups (Table 4). For animals that survived until termination, there were no macroscopic changes at necropsy that could be attributed to the administration of high-dose
NRMR. Similarly, no corresponding gross or microscopic pathological changes in these organs were observed.

\section{DISCUSSION}

In drug therapy applications, many drugs such as danazol, naproxen, etoposide, piposulfan, camptothecin, paclitaxel, and $\mathrm{Zn}$-insulin are made into nanoparticulate dispersions $(34,35)$ to provide beneficial effects such as improved bioavailability, improved dose proportionality, reduced organ irritation, reduced fed/fasted variability, and enhanced absorption rate (17) and as certified dietary supplements (21). In our previous study, we reported a method for preparing nanoparticulate RMR dispersion by a wet milling process (mean particle size $=410 \mathrm{~nm}$ ) $(15)$. Under controlled temperature, the processing parameters that influence NRMR particle size include milling time, particle size and composition of grinding media, and types of dispersion stabilizer used. During size reduction in the ball mill grinding, the number of contact points and the efficiency of grinding and dispersing increase exponentially with decreasing particle size of grinding media. Hence, in this study, we use yttria-stabilized tetragonal zirconia polycrystal (Y-TZP) beads as the grinding media (mean particle size $=0.1 \mathrm{~mm}$ ). Besides avoiding the exceptional toxicity found in common wet milling equipment, Y-TZP offers a combination of properties (high hardness, fracture toughness, spherical shape, and chemical stability) that makes them very suitable for use in this study (36). Figure 1 shows the chronic size reduction curve during the ball milling of RMR, fermented with the mutant $M$. purpureus NTU 568, into nanoparticulate dispersion (mean particle size $=259.3 \mathrm{~nm}$ ). 
Table 6. Serum Biochemistry Change of Male and Female Rats Treated with Red Mold Rice and Nanoparticulate Red Mold Rice by Gastric Gavage Consecutively for 90 Days

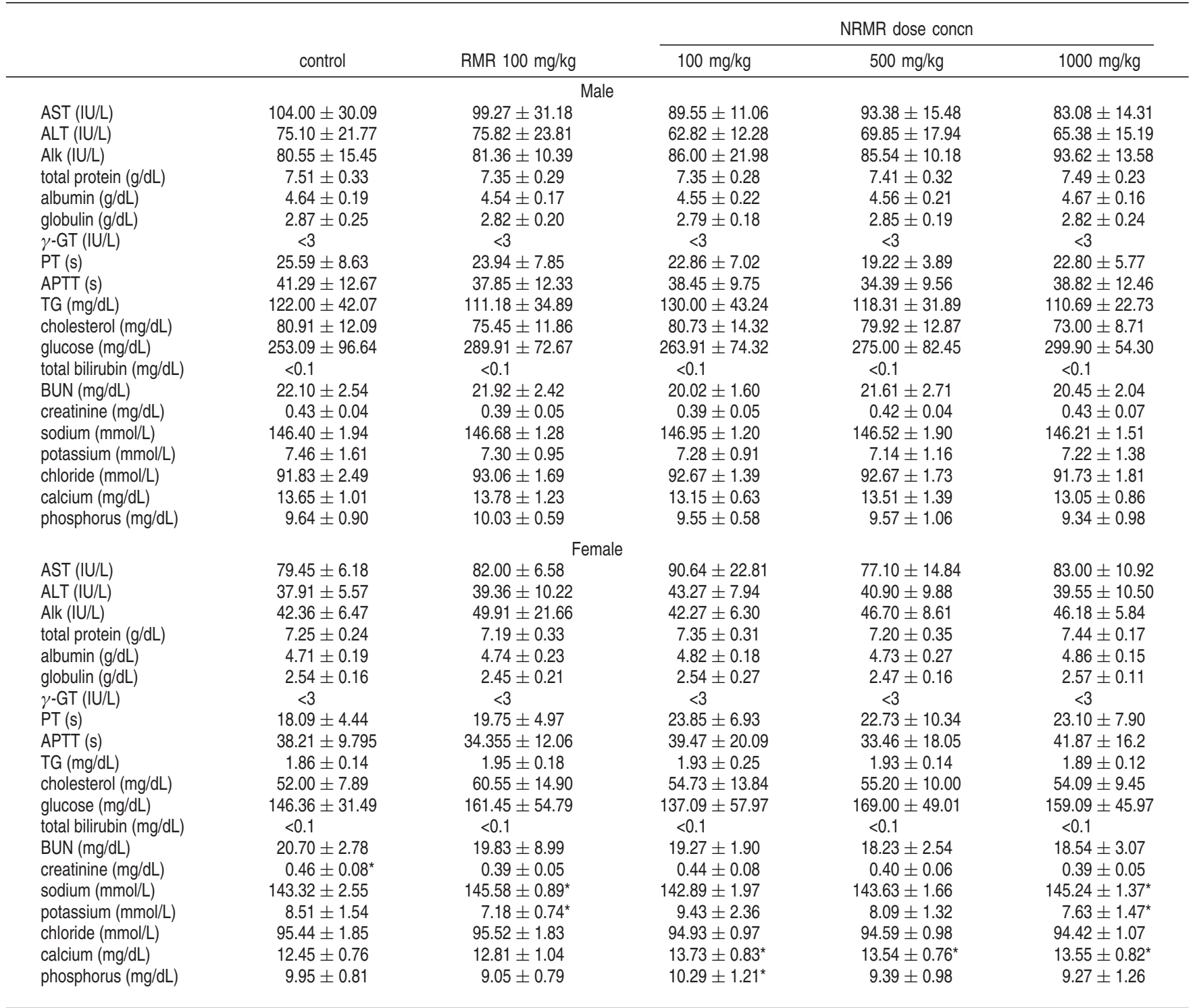

* Data are presented as mean $\pm \mathrm{SD}(n=10)$. Mean values within each column with an asterisk are significantly different $(p<0.05)$. AST, aspartate aminotransferase; ALT, alanine aminotransferase; Alk, alkaline phosphatase; $\gamma$-GT, $\gamma$-glutamyl transpeptidase; PT, prothrombin time; APTT, activated partial thromboplastin time; TG, triglycerides; BUN, blood urea nitrogen.

As a mixture of carbohydrate, protein, and fat, the fermented RMR may also fuction as a dispersion stabilizer to form a selfstabilized nanodispersion (15). During secondary metabolite analyses by HPLC, the contents of monacolin $\mathrm{K}$ and citrinin in NRMR dispersion were found to be $5651 \mathrm{mg} / \mathrm{kg}$ and $1048 \mu \mathrm{g} /$ $\mathrm{kg}$, respectively. Interestingly, the high monacolin $\mathrm{K} /$ citrinin ratio found in the secondary metabolites of RMR fermented with $M$. purpureus 568 strain was preserved after three-step ball milling (Figures 2 and 3). That is, the secondary metabolite content was maintained after size reduction via the three-step wet milling process and thus simplified the subsequent in vitro and in vivo studies.

The Ames/Salmonella assay utilizes specific genetically constructed strains of Salmonella bacteria and mammalian metabolic activation enzyme (S9) to identify many mutagenic chemicals from various sources. S9 is a rodent metabolic activation system introduced into the test system. The metabolic activation system usually consists of a $9000 \mathrm{~g}$ supernatant fraction of a rat liver homogenate ( $\mathrm{S} 9$ microsomal fraction), which is delivered to the test system in the presence of NADP and cofactors for NADPH-supported oxidation (37). The degree of mutagenicity could be determined when $85 \%$ of the carcinogens were tested (27). Before the Ames test was conducted, the genotype pretests for all of the test strains were needed to ensure the reliability of their mutation efficiency. TA 98 is mainly used to test for frameshift mutation, TA 100 is for basepair substitution, and TA 102 is for transition/transversion mutation (37). Table 1 shows that when testing nonmilling RMR extract in the standard $S$. typhimurium assay, none of the three strains tested showed any mutagenic response with or without the presence of S9 mix. In addition, there was no dose-dependent increase in mutagenicity for all three test strains when NRMR extract was tested. In conclusion, RMR extracts were not mutagenic without the activation by $\mathrm{S} 9$ mix before and after the wet milling process in the Ames test. In a previous study (25), citrinin and RMR were not found to be mutagenic with or without activation by S9 mix in the standard Ames test. However, RMR with high concentration of citrinin (within $8.4-17.1 \mu \mathrm{g} / \mathrm{g}$ ) induced mutagenic response in $S$. typhimurium strain TA 98 after metabolic activation by hepatocytes. The 
Salmonella-hepatocyte assay was applied to evaluate the possible contribution of biotransformation pathways to citrinin mutagenicity. Compared with the more common RMR with high concentration of citrinin, the RMR used in this study was determined to contain relatively high monacolin $\mathrm{K}$ and low citrinin concentration $(=1.0 \mu \mathrm{g} / \mathrm{kg})(12)$ and was not mutagenic even under the conditions of alternative metabolic pathways. In this study, we used strain TA 102, which was expected to be sensitive to oxidize mutagens (38), yet our results showed that high levels of NRMR extract were not mutagenic to this or other strains.

As can be seen from Figures $\mathbf{4}$ and $\mathbf{5}$ and Tables $\mathbf{2}$ and $\mathbf{3}$, there were no evidence of toxic effect as determined by hematology, food consumption, gross necropsy, and histopathology in the 28-day repeated feeding of RMR in the diet. However, in clinical biochemistry measurement (Table 3), the data obtained from the highest dosage NRMR-treated groups (1000 mg/kg of body wt /day), unlike those obtained from the control diet group, were found to fall outside the acceptable range of the reference data $(32,33)$. This finding corresponded to an increase in alanine aminotransferase, glucose, and blood urea nitrogen in male rats, which may be related to a slight physiological disturbance following high dietary administration of NRMR. Furthermore, none of above-mentioned findings were supported by histopathological changes. The toxicological significance is questionable. For further study of possible NRMR toxicity during prolonged treatment, the repeated-dose 28-day oral toxicity study was extended to 90 days.

In the 90-day repeated feeding test, NRMR intake through gavage was carried out well enough that it did not produce any general organ or systemic toxicity in male and female rats for doses as high as $1000 \mathrm{mg} / \mathrm{kg}$ of body wt/day for the period of 90 days. Tables 4-6 show that there was no evidence of organ weight change, macroscopic change at necropsy, and histological change that was attributed to the NRMR treatment. In addition, these doses did not produce any effect on food consumption and body weight changes or cause any treatment-related clinical signs. Although minor changes in hematology and clinical chemistry parameters were observed, these changes were within the acceptable range of reference data and were considered to be of no biological or toxicological significance $(32,33)$.

For a thousand years, the RMR fermented by $M$. purpureus has been used as a food coloring agent, flavoring, and preservative (1). Nowadays, RMR is widely used as a dietary supplement because of its cholesterol-lowing effect (5). In addition, RMR contains many secondary metabolites that were reported to fuction as anti-hypertension (6), antioxidants (7), and antifatigue agents (39) and as enhancer for memory and learning ability (40). It is well-known that RMR has dual functions: one is to function as a provider of the cholesterol-lowering agent monacolin, and the other is to act as the carrier of citrinin, which is a mycotoxin (9). Both fuctions of RMR are well documented. For instance, lovastatin, the analogue of monacolin K, has been marketed as a prescription drug for treating hyperlipidemia since 1987. In primary prevention of acute coronary events, lovastatin (20-40 mg daily) can reduce the risk for the first major coronary event in persons with average total cholesterol (TC) and lowdensity lipoprotein cholesterol (LDL-C) levels and belowaverage high-density lipoprotein cholesterol (HDL-C) levels (41). On the other hand, statins are blamed for significant toxic effects, which include the increase in concentration of hepatic transaminases, the atypical focal hyperplasia of the liver, cataracts, vascular lesions in the central nervous system, skeletal muscle toxicity, and testicular degeneration at high doses $(42,43)$.
In animal studies of statins, the toxicity caused by high dosage $(100-200 \mathrm{mg} / \mathrm{kg}$ of body wt/day for animal species such as rabbits) was found to be 100 times higher than that caused by the therapeutic dosage (not exceeding $20 \mathrm{mg} /$ day) (44), which was administered to lower human serum cholesterol levels (43). In our feeding study, the highest dosage contained about 5.65 $\mathrm{mg} / \mathrm{kg}$ of body wt/day monacolin $\mathrm{K}$, which was far less than the toxic dose in rabbits. In contrast, the feeding of citrinin, an antibiotic, was reported to cause multiple effects that resulted in cell death $(10,26)$. During in vivo studies, citrinin was also known to function as a hepatonephrotoxin against a wide range of animal species $(8,45-47)$. The $72-\mathrm{h} \mathrm{LD}_{50}$ of citrinin was $112 \mathrm{mg} / \mathrm{kg}$ of body wt by the oral route in mice (45), $220 \mathrm{mg} /$ $\mathrm{kg}$ of body wt in Syrian hamster (46), and $134 \mathrm{mg} / \mathrm{kg}$ of body wt in rabbits (47) in a single dose. In our safety study, the overall dose of citrinin given to the high dosage group $(0.1 \mathrm{mg} / \mathrm{kg}$ of body wt/90 days) is 1000 times less than the $72-\mathrm{h} \mathrm{LD}_{50}$ in mice (112 $\mathrm{mg} / \mathrm{kg}$ of body wt) due to our limited access to citrinin from RMR which was fermented with the low citrinin producing Monascus strain (12). In this study, both in vitro and in vivo studies of RMR revealed no mutagenic or toxic response, either before or after the nanopartiulation process.

Many animal studies have been carried out to address safety concerns about RMR. Chickens, rabbits, and hamsters were used as animal models to prove the anti-hyperlipidermia effect $(2,48,49)$. In a related safety evaluation, Monascus pigment has been reported to be nontoxic for rats (50). Its acute toxicity was determined to be $33.3 \mathrm{~g} / \mathrm{kg}$ of body weight, which is below its $50 \%$ lethal dose $\left(\mathrm{LD}_{50}\right)$. A 90-day repeated-dose test showed no evidence of toxic effects as determined by hematology, blood clinical chemistry, food consumption, gross necropsy, and histopathology when $16 \%$ Monascus pigment was added to the animals' daily intake (= 100 times the typical human dose). These data confirm that Monascus pigment is safe to use as food additive. The adverse effects caused by food/drug interactions encountered during human trials of RMR are relatively low when compared with the commercial HMG-CoA reductase inhibitors $(4,51,52)$. In the United States, 83 healthy subjects with hyperlipidermia treated with RMR ( $2.4 \mathrm{~g} /$ day $)$ or placebo for 12 weeks revealed that their levels of TC, LDL-C, and total triacylglycerol (TG) were significantly lower in the RMR-treated group than the placebo-treated group (4). During the test, however, the level of HDL-C was not changed significantly. Besides, there were no signs of abnormal liver or renal function reported after the test (4). In another study conducted in Italy, 111 Caucasian subjects were treated with the M. purpureus brand dietary supplement and showed significant decreases of TC, LDL-C, and TG in moderately hypercholesterolemic subjects without clinically relevant increases in liver and muscular toxicity (51). In Taiwan, where the Health Food Control Act came into effect on February 3, 1999, four Monascus products were proved to be effective in regulating blood cholesterol level and are officially certified as health foods (53). Furthermore, the newly developed LipoCol Forte Cap (Naturewise, Taipei, Taiwan), a cholesterol-lowering drug, is the first new Chinese medicine certified by the Department of Health in 2005 (drug code 047152).

On the basis of the findings from the 90-day repeated-dose oral toxicity study, the no observed adverse effect level (NOAEL) is $1000 \mathrm{mg} / \mathrm{kg}$ of body wt/day for male rats (mean weight $=410 \mathrm{~g}$ ) and female rats (mean weight $=275 \mathrm{~g}$ ). According to Boyd's formula of body surface area recommended by the FDA (54), this was translated into a daily dosage of 14.45 $\mathrm{g}$ of NRMR for a man with a weight of $65 \mathrm{~kg}$ and a height of 
$170 \mathrm{~cm}$, and such a dosage contains $81.64 \mathrm{mg}$ of monacolin $\mathrm{K}$ and $15.14 \mu \mathrm{g}$ of citrinin. In other words, this meant a daily consumption of $11.42 \mathrm{~g}$ of NRMR for a woman with a weight of $55 \mathrm{~kg}$ and a height of $160 \mathrm{~cm}$, and such a dosage contains $64.52 \mathrm{mg}$ of monacolin $\mathrm{K}$ and $11.97 \mu \mathrm{g}$ of citrinin.

There are still arguments about which dietary supplement category RMR can fit in $(55,56)$. From the viewpoint of the food industry, when served as a dietary supplement, RMR can act like a cholesterol-lowering agent through the collaborative action of several ingredients such as monacolins, phytosterols, and other Monascus pigments (52), although it is considered to be expensive (4). In summary, this study focused on assessing the safety of NRMR formulation by in vitro mutagenicity and in vivo subcronic toxicity test. The data show that high levels of NRMR are neither genotoxic in vitro nor systemically toxic following subchronic administration in the diet at levels up to $1000 \mathrm{mg} / \mathrm{kg}$ of body wt for 28 and 90 consecutive days in the rat. For this reason, our preparation method for nanoparticulate RMR can be used as a reference model for formulating nanodispersions of other dietary supplement.

\section{LITERATURE CITED}

(1) Su, Y. C.; Chen, W. L.; Lee, Y. H. Studies on the anka pigment product by a mutant of Monascus anka. Mem. Coll. Agric., Natl. Taiwan Univ. 1973, 14, 41-56 (in Chinese).

(2) Li, C. L.; Zhu, Y.; Wang, Y. Y.; Zhu, J. S.; Chang, J.; Kritchevsky, D. Monascus purpureus-fermented rice (red yeast rice): A natural food product that lowers blood cholesterol in animal models of hypercholesterolemia. Nutr. Res. (N.Y.) 1998, 18, 71-81.

(3) Su, Y. C.; Wang, J. J.; Lin, T. T.; Pan, T. M. Production of the secondary metabolites $\gamma$-aminobutyric acid and monacolin $\mathrm{K}$ by Monascus. J. Ind. Microbiol. Biotechnol. 2003, 30, 41-46.

(4) Heber, D.; Yip, I.; Ashley, J. M.; Elashoff, D. A.; Elashoff, R. M.; Go, V. L. Cholesterol-lowering effects of a proprietary Chinese red-yeast-rice dietary supplement. Am. J. Clin. Nutr. 1999, 69, 231-236.

(5) Endo, A. Monacolin K, a new hypocholesterolemic agent produced by a Monascus species. J. Antibiot. (Tokyo) 1979, 32, 852-854.

(6) Kohama, Y.; Matsumoto, S.; Mimura, T.; Tanabe, N.; Inada, A.; Nakanishi, T. Isolation and identification of hypotensive principles in red-mold rice. Chem. Pharm. Bull (Tokyo) 1987, 35, 24842489.

(7) Aniya, Y.; Yokomakura, T.; Yonamine, M.; Nagamine, T.; Nakanishi, H. Protective effect of the mold Monascus anka against acetaminophen-induced liver toxicity in rats. Jpn. J. Pharmacol. 1998, 78, 79-82.

(8) Kitabatake, N.; Doi, E.; Trivedi, A. B. Toxicity evaluation of the mycotoxins, citrinin and ochratoxin A, using several animal cell lines. Comp. Biochem. Physiol. C. 1993, 105, 429-433.

(9) Blanc, P. J.; Laussac, J. P.; Le Bars, J.; Le Bars, P.; Loret, M. O.; Pareilleux, A.; Prome, D.; Prome, J. C.; Santerre, A. L.; Goma, G. Characterization of monascidin A from Monascus as citrinin. Int. J. Food Microbiol. 1995, 27, 201-213.

(10) Kitabatake, N.; Trivedi, A. B.; Doi, E. Thermal decomposition and detoxification of citrinin under various moisture conditions. J. Agric. Food Chem. 1991, 39, 2240-2244.

(11) Fouler, S. G.; Trivedi, A. B.; Kitabatake, N. Detoxification of citrinin and ochratoxin A by hydrogen peroxide. J. AOAC Int. 1994, 77, 631-637.

(12) Wang, J. J.; Lee, C. L.; Pan, T. M. Modified mutation method for screening low citrinin-producing strains of Monascus purpureus on rice culture. J. Agric. Food Chem. 2004, 52, 69776982.

(13) Lee, C. L.; Chen, W. P.; Wang, J. J.; Pan, T. M. A simple and rapid approach for removing citrinin while retaining monacolin $\mathrm{K}$ in red mold rice. J. Agric. Food Chem. 2007, 55, 11101-11108.
(14) Trivedi, A. B.; Doi, E.; Kitabatake, N. Toxic compounds formed on prolonged heating of citrinin under watery conditions. J. Food Sci. 1993, 58, 229-232.

(15) Yu, C. C.; Lee, C. L.; Pan, T. M. A novel formulation approach for preparation of nanoparticulate red mold rice. J. Agric. Food Chem. 2006, 54, 6845-6851.

(16) Salata, O. V. Applications of nanoparticles in biology and medicine. J. Nanobiotechnol. 2004, 2, 3.

(17) Muller, R. H.; Jacobs, C.; Kayser, O. Nanosuspensions as particulate drug formulations in therapy: rationale for development and what we can expect for the future. Adv. Drug Delivery Rev. 2001, 47, 3-19.

(18) Merisko-Liversidge, E.; Liversidge, G. G.; Cooper, E. R. Nanosizing: a formulation approach for poorly-water-soluble compounds. Eur. J. Pharm. Sci. 2003, 18, 113-120.

(19) Hoet, P. H.; Bruske-Hohlfeld, I.; Salata, O. V. Nanoparticles-known and unknown health risks. J. Nanobiotechnol. 2004, 2, 12.

(20) Donaldson, K.; Stone, V.; Tran, C. L.; Kreyling, W.; Borm, P. J. Nanotoxicology. Occup. Environ. Med. 2004, 61, 727-728.

(21) Jia, X.; Li, N.; Chen, J. A subchronic toxicity study of elemental nano-Se in Sprague-Dawley rats. Life Sci. 2005, 76, 1989-2003.

(22) Lee, C. L.; Hung, H. K.; Wang, J. J.; Pan, T. M. Improving the ratio of monacolin $\mathrm{K}$ to citrinin production of Monascus purpureus NTU 568 under dioscorea medium through the mediation of $\mathrm{pH}$ value and ethanol addition. J. Agric. Food Chem. 2007, 55, 64936502.

(23) Pecora, R. Dynamic light scattering measurement of nanometer particles in liquids. J. Nanopart. Res. 2000, 2, 123-131.

(24) Lee, C. L.; Wang, J. J.; Pan, T. M. Synchronous analysis method for detection of citrinin and the lactone and acid forms of monacolin $\mathrm{K}$ in red mold rice. J. AOAC Int. 2006, 89, 669-677.

(25) Sabater-Vilar, M.; Maas, R. F. M.; Fink-Gremmels, J. Mutagenicity of commercial Monascus fermentation products and the role of citrinin contamination. Mutat. Res. 1999, 444, 7-16.

(26) Liu, B. H.; Wu, T. S.; Su, M. C.; Chung, C. P.; Yu, F. Y. Evaluation of citrinin occurrence and cytotoxicity in Monascus fermentation products. J. Agric. Food Chem. 2005, 53, 170-175.

(27) Ames, B. N.; McCann, J.; Yamasaki, E. Methods for detecting carcinogens and mutagens with the Salmonella/mammalianmicrosome mutagenicity test. Mutat. Res. 1975, 31, 347-364.

(28) OECD Guidelines for the Testing of Chemicals Test 471: Bacterial Reverse Mutation Test; OECD: Paris, France, adopted 1997; http:// masetto. sourceoecd.org $/ \mathrm{vl}=3461816 / \mathrm{cl}=11 / \mathrm{nw}=1 / \mathrm{rpsv} / \mathrm{cw} /$ vhosts /oecdjournals/1607310x/v1n4/contp1-1.htm.

(29) OECD Guidelines for the Testing of Chemicals Test 407: Repeated Dose 28-Day Oral Toxicity Study in Rodents; OECD: Paris, France, adopted 1995; http://miranda.sourceoecd.org/vl=382735 /cl=15/nw=1/rpsv/cw/vhosts/oecdjournals/1607310x/v1n4/contp11.htm.

(30) OECD Guidelines for the Testing of Chemicals Test 408: Repeated Dose 90-Day Oral Toxicity Study in Rodents; OECD: Paris, France, adopted 1998; http://miranda.sourceoecd.org/vl=382735/ $\mathrm{cl}=15 / \mathrm{nw}=1 / \mathrm{rpsv} / \mathrm{cw} /$ vhosts/oecdjournals/1607310x/v1n4/contp11.htm.

(31) Report of the American Institute of Nutrition ad hoc committee on standards for nutritional studies J. Nutr. 1977, 107, 13401348.

(32) Baseline Hematology and Clinical Chemistry Values for Charles River Wistar Rats [Crl:(WI)BR] as a Function of Sex and Age; Charles River Laboratories, Inc.: Wilmington, MA, 1998; http:// www.criver.com/en-US/ProdServ/ByType/ResModOver/Pages/ On-lineLiterature.aspx.

(33) Olfert, E. D.; Cross, B. M.; McWilliam, A. A. Guide to the Care and Use of Experimental Animals; Canadian Council on Animal Care: Ottawa, Canada, 1993; http://www.ccac.ca/en/CCAC_ Programs/Guidelines_Policies/PDFs/ExperimentalAnimals_GDL. pdf. 
(34) Merisko-Liversidge, E.; Sarpotdar, P.; Bruno, J.; Hajj, S.; Wei, L.; Peltier, N.; Rake, J.; Shaw, J. M.; Pugh, S.; Polin, L.; Jones, J.; Corbett, T.; Cooper, E.; Liversidge, G. G. Formulation and antitumor activity evaluation of nanocrystalline suspensions of poorly soluble anticancer drugs. Pharm. Res. 1996, 13, 272-278.

(35) Merisko-Liversidge, E.; McGurk, S. L.; Liversidge, G. G. Insulin nanoparticles: a novel formulation approach for poorly water soluble Zn-insulin. Pharm. Res. 2004, 21, 1545-1553.

(36) Farber, B. Y.; Graves, G. A. Ceramic media with improved efficiency. PCI 2001, (April), 30-41.

(37) Mortelmans, K.; Zeiger, E. The Ames Salmonella/microsome mutagenicity assay. Mutat. Res. 2000, 455, 29-60.

(38) Levin, D. E.; Hollstein, M.; Christman, M. F.; Schwiers, E. A.; Ames, B. N. A new Salmonella tester strain (TA102) with A-T base pairs at the site of mutation detects oxidative mutagens. Proc. Natl. Acad. Sci. U.S.A. 1982, 79, 7445-7449.

(39) Wang, J. J.; Shieh, M. J.; Kuo, S. L.; Lee, C. L.; Pan, T. M. Effect of red mold rice on antifatigue and exercise-related changes in lipid peroxidation in endurance exercise. Appl. Microbiol. Biotechnol. 2006, 70, 247-253.

(40) Lee, C. L.; Kuo, T. F.; Wang, J. J.; Pan, T. M. Red mold rice ameliorates impairment of memory and learning ability in intracerebroventricular amyloid beta-infused rat by repressing amyloid beta accumulation. J. Neurosci. Res. 2007, 85, 31713182.

(41) Downs, J. R.; Clearfield, M.; Weis, S.; Whitney, E.; Shapiro, D. R.; Beere, P. A.; Langendorfer, A.; Stein, E. A.; Kruyer, W.; Gotto, A. M., Jr. Primary prevention of acute coronary events with lovastatin in men and women with average cholesterol levels: results of AFCAPS/TexCAPS. JAMA-J. Am. Med. Assoc. 1998, 279, 1615-1622.

(42) MacDonald, J. S.; Gerson, R. J.; Kornbrust, D. J.; Kloss, M. W.; Prahalada, S.; Berry, P. H.; Alberts, A. W.; Bokelman, D. L. Preclinical evaluation of lovastatin. Am. J. Cardiol. 1988, 62, 16J27J

(43) Kornbrust, D. J.; MacDonald, J. S.; Peter, C. P.; Duchai, D. M.; Stubbs, R. J.; Germershausen, J. I.; Alberts, A. W. Toxicity of the HMG-coenzyme A reductase inhibitor, lovastatin, to rabbits. J. Pharmacol. Exp. Ther. 1989, 248, 498-505.
(44) MEVACOR product information; Merck \& Co., Inc., Whitehouse Station, NJ, 1996; http://www.fda.gov/cder/foi/label/2002/ 19643s067lbl.pdf.

(45) Jordan, W. H.; Carlton, W. W.; Sansing, G. A. Citrinin mycotoxicosis in the mouse. Food Cosmet. Toxicol. 1977, 15, 29-34.

(46) Jordan, W. H.; Carlton, W. W.; Sansing, G. A. Citrinin mycotoxicosis in the syrian hamster. Food Cosmet. Toxicol. 1978, $16,355-363$.

(47) Hanika, C.; Carlton, W. W.; Tuite, J. Citrinin mycotoxicosis in the rabbit. Food Cosmet. Toxicol. 1983, 21, 487-493.

(48) Wang, J. J.; Pan, T. M. Effect of red mold rice supplements on serum and egg yolk cholesterol levels of laying hens. J. Agric. Food Chem. 2003, 51, 4824-4829.

(49) Wang, J. J.; Pan, T. M.; Shieh, M. J.; Hsu, C. C. Effect of red mold rice supplements on serum and meat cholesterol levels of broilers chicken. Appl. Microbiol. Biotechnol. 2006, 71, 812-818.

(50) Su, Y. C.; Huang, T. L. Animal feeding test for Monascus pigment. Mem. College Agric., Natl. Taiwan Univ. 1981, 21, 98-112 (in Chinese).

(51) Cicero, A. F. G.; Brancaleoni, M.; Laghi, L.; Donati, F.; Mino, M. Antihyperlipidaemic effect of a Monascus purpureus brand dietary supplement on a large sample of subjects at low risk for cardiovascular disease: a pilot study. Complem. Ther. Med. 2005, 13, 273-278.

(52) Li, Z.; Seeram, N. P.; Lee, R.; Thames, G.; Minutti, C.; Wang, H. J.; Heber, D. Plasma clearance of lovastatin versus Chinese red yeast rice in healthy volunteers. J. Altern. Complement Med. 2005, 11, 1031-1038.

(53) Health Food Control Act; Department of Health, Taipei, Taiwan, 1999; http://food.doh.gov.tw/english/Acts_Regulations/ Healthfood_1.asp?lawsidx $=417$.

(54) Dose Calculator; U.S. Food and Drug Administration http:// www.fda.gov/cder/ cancer/animalframe.htm.

(55) McCarthy, M. FDA bans red yeast rice product. Lancet 1998, $351,1637$.

(56) Havel, R. J. Dietary supplement or drug? The case of cholestin. Am. J. Clin. Nutr. 1999, 69, 175-176.

Received for review December 30, 2007. Revised manuscript received September 10, 2008. Accepted September 30, 2008.

JF801335U 